\title{
New phosphonate-mediated syntheses of cyclopentanoids and prostaglandins*
}

\author{
Marian Mikolajczyk, $\uparrow$ Maciej Mikina and Remigiusz Zurawinski \\ Center of Molecular and Macromolecular Studies, Polish Academy of Sciences, \\ 90-363 Lódz, Sienkiewicza 112, Poland
}

\begin{abstract}
This account outlines the results obtained in the author's laboratory on the application of phosphonate reagents in the synthesis of biologically active cyclopentanones and cyclopentenones. The synthesis and reactivity of 3-phosphorylmethyl-cycloalkenones is discussed as a platform for developing the first synthesis of enantiomeric isoterreins as well as the synthesis of racemic and optically active prostaglandins $B_{1 \alpha}$. A different strategy for the total synthesis of racemic and enantiomeric forms of sarkomycin and rosaprostol is described which involves in a key step intramolecular carbenoid cyclization of the corresponding $\alpha$-diazo- $\beta$-ketophosphonates.
\end{abstract}

\section{INTRODUCTION}

The cyclopentanone and cyclopentenone structural units are present in a wide range of important natural products such as jasmonoids, cyclopentanoid antibiotics and prostaglandins. The broad spectrum of biological activity of this type of compounds has prompted an extensive search for development of new methods of their preparation. Although structures of these natural products are relatively simple, their synthesis is not trivial because of the low chemical stability of many of these compounds and specific functionalization of the five-membered ring. As part of our broad program on the application of phosphorus and sulfur compounds in organic synthesis [1,2] we have also been engaged over the last decade or so in the invention and development of general methods for the synthesis of functionalized cyclopentanones and cyclopentenones. These endeavours have culminated in the elaboration of new and efficient routes to dihydrojasmone 1 [3], cis-jasmone 2 [4] and methylenomycin B 3 [5,6] (Scheme 1).
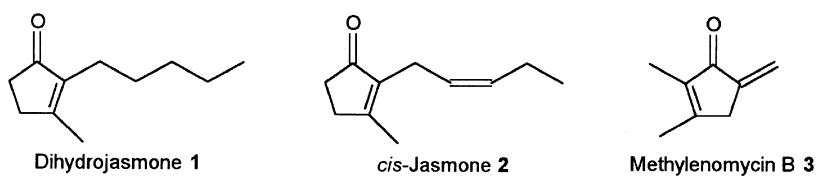

Scheme 1

The aim of the present account is to summarize the recent results obtained in the author's laboratory on the phosphonate-mediated synthesis of both enantiomeric forms of isoterrein $\mathbf{4}$ and sarkomycin $\mathbf{5}$, racemic and optically active prostaglandins $B_{1 \alpha} 6$ and racemic rosaprostol 7 (Schemes 2, 3).

\section{SYNTHESIS AND REACTIVITY OF BIS- $\beta$-KETOPHOSPHONATES AND 3- (PHOSPHORYLMETHYL)-CYCLOALKENONES}

Before presenting our synthesis of isoterrein 4 and prostaglandin $B_{1 \alpha} 6$, it seems desirable to discuss

\footnotetext{
*Lecture presented at the 5th International Conference on Heteroatom Chemistry (ICHAC-5), London, Ontario, Canada, 5-10 July 1998, pp. 369-512.

$\dagger$ Corresponding author: E-mail: marmikol@bilbo.cbmm.lodz.pl
} 
<smiles>C/C=C/C1=CC(=O)[C@H](O)[C@@H]1O</smiles>

$(-)-(4 S, 5 S)$-Isoterrein 4

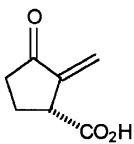

$(-)-(R)-$ Sarkomycin 5

\section{Scheme 2}<smiles>CCC(C)C(C)=CC1=C(C)C(=O)CC1</smiles>

Prostaglandin $\mathrm{B}_{1 \alpha} 6$<smiles>CC[C@H]1CCC(O)C1CC(=O)O</smiles>

Rosaprostol 7

\section{Scheme 3}

briefly the synthesis of bis- $\beta$-ketophosphonates $\mathbf{8}$ and 3-(phosphorylmethyl)-cycloalkenones $\mathbf{9}$ as well as the reactivity of the latter [7]. These basic studies allowed the development of a new methodology for the synthesis of the targets $\mathbf{4}$ and $\mathbf{6}$ mentioned above.

It was found that bis- $\beta$-ketophosphonates $\mathbf{8}$ could be easily obtained in the reaction between $\alpha$-phosphonate carbanions and dicarboxylic acid esters. The intramolecular base-catalyzed cyclization of 8 afforded in good yields cycloalkenones 9 (Scheme 4).

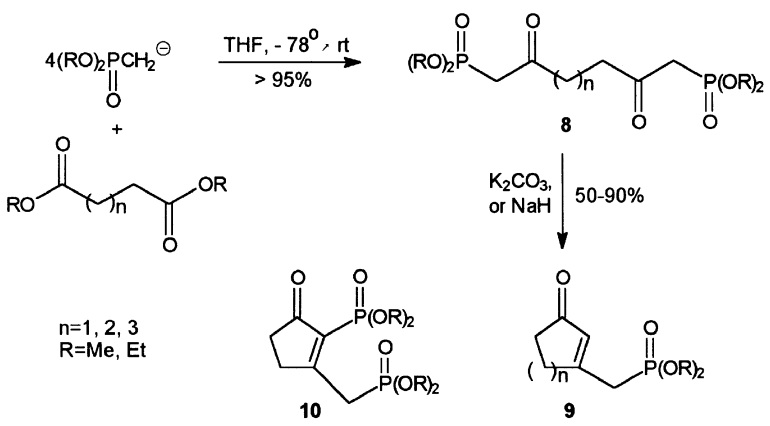

\section{Scheme 4}

It is interesting to point out that the kinetically controlled product of this reaction is the Knoevenagel product $\mathbf{1 0}$ which is converted into the final Horner-Wittig reaction product $\mathbf{9}$ under basic reaction conditions.

The structure of the cycloalkenone $\mathbf{9}$ offers many possibilities for further eleboration. Especially interesting is the reactivity of the anion derived from 9 because negative charge in this anion is distributed among several atoms as indicated by the hydrogen-deuterium exchange experiments. It was demonstrated that alkylation of this anion occurs at the $\alpha$-carbonyl carbon atom, acylation takes place at oxygen, and carbonyl compounds react at the phosphonate carbon atom affording the HornerWittig olefination prducts.Selected examples illustrating the reactivity of the anion $\mathbf{9}^{-}$are collected in Scheme 5 .

The ketophosphonate chemistry briefly presented above indicates that the cycloalkenones 9 can be easily functionalized and therefore can serve as synthetic intermediates in the synthesis of natural products.

\section{SYNTHESIS OF OPTICALLY ACTIVE ISOTERREIN}

(+)-Terrein 11, a metabolite of Aspergillus terreus isolated in 1935 by Raistrick \& Smith [8], belongs to the family of cyclopentanoids. Although its synthesis attracted considerable attention, only recently two research groups $[9,10]$ succeeded in synthesizing enantiomeric $(+)$-and (-)-terrein 11 (Scheme 6). 


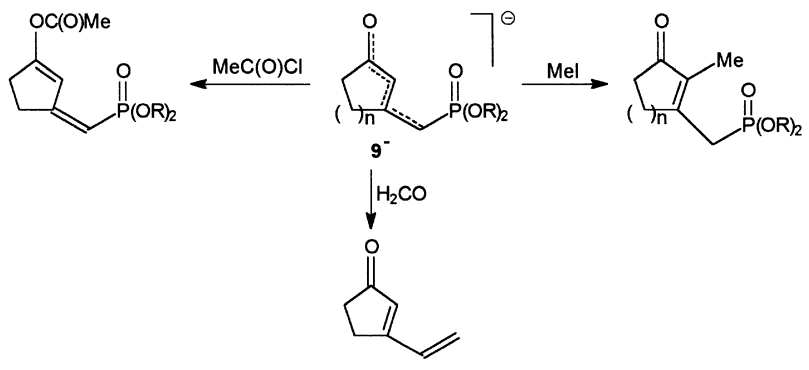

Scheme 5

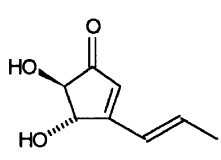

$(+)-(R, R)$-Terrein 11

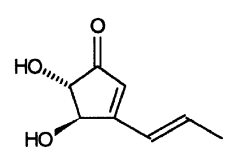

$(-)-(S, S)$-Terrein 11

\section{Scheme 6}

Isoterrein 4, which is the more stable isomer of terrein $\mathbf{1 1}$ and has cis-configuration of the diol moiety, was obtained only in racemic form by Barton \& Hulshof [11] more than 20 years ago. Therefore, we turned our attention to the synthesis of enantiomeric isoterreins 4 . Our first attempt [12] at the preparation of optically active 4 utilizing our bis- $\beta$-ketophosphonate chemistry is shown in Scheme 7.<smiles>COC(=O)C1OC(c2ccccc2)O[C@@H]1C(=O)OCc1ccccc1</smiles><smiles>CC(=O)CC(=O)C1OC(c2ccccc2)OC1C(=O)CC(C)=O</smiles>

13 $80 \% \mid \begin{aligned} & \mathrm{K}_{2} \mathrm{CO}_{3}, 18-\mathrm{C}-6 \\ & \mathrm{C}_{6} \mathrm{H}_{6}, 400 \mathrm{C}\end{aligned}$

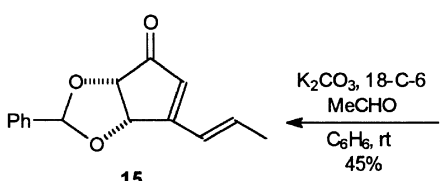

15

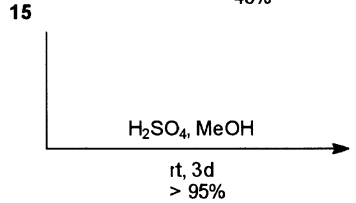<smiles>COC(=O)CC1=CC(=O)[C@@H]2OC(c3ccccc3)O[C@H]12</smiles>

14

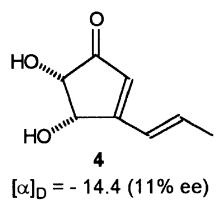

Scheme 7

The protected derivative of (-)-dimethyl tartrate $\mathbf{1 2}$ was treated with dimethyl lithiomethylphosphonate to give the corresponding bis- $\beta$-ketophosphonate $\mathbf{1 3}$. Base-catalyzed cyclization of $\mathbf{1 3}$ afforded the cyclopentenone $\mathbf{1 4}$ which was next reacted with acetaldehyde to give the Horner-Wittig product $\mathbf{1 5}$. Deprotection of the diol moiety in $\mathbf{1 5}$ resulted in the formation of optically active (-)-isoterrein $\mathbf{4}$. Its optical purity was, however, extremely low (11\%).

It should be emphasized that during the above synthesis one observes the trans- to cis-isomerization of the chiral diol unit. Most probably, the cyclopentenone 14a that should be primarily formed from 13 undergoes isomerization via the enolate anion to give the more stable cyclopentenone $\mathbf{1 4}$ with the cis-diol moiety (Scheme 8).

A high extent of racemization of (-)-isoterrein 4 obtained in this way my be rationalized in terms of a 


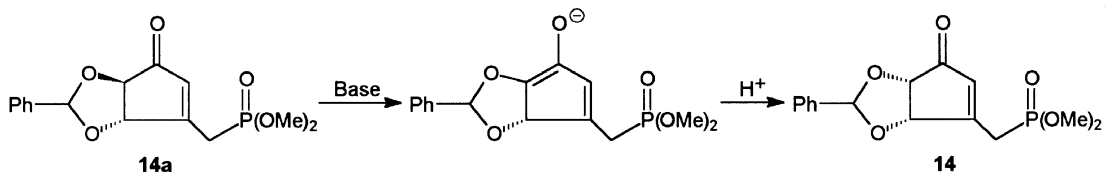

Scheme 8

reversibility of the cyclization reaction and fast proton transfer between the bis- $\beta$-ketophosphonate anions transiently formed as shown below (Scheme 9).<smiles></smiles><smiles>CP(C)(=O)CC(=O)C1OC(c2ccccc2)O[C@H]1C(=O)CP(C)(C)=O</smiles>

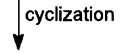<smiles>C1C[C@H]2CC12</smiles><smiles>CP(C)(=O)CC1=CC(=O)C2OC(c3ccccc3)OC12</smiles><smiles>CP(C)(=O)CC1=CC(=O)[C@H]2OC(c3ccccc3)O[C@H]12</smiles>

\section{Scheme 9}

In developing the strategy for the synthesis of both enantiomers of isoterrein 4 we noted that mesotartaric acid has the same cis-configuration of the diol moiety [13]. So, it could serve as a suitable substrate provided that it can be converted into optically active derivative. It was gratifying to find that a complete desymmetrization of meso-tartaric acid was occurring in the acid-catalyzed reaction with (+)camphor and methyl orthoformate (eqn 1, Scheme 10). A single diastereomer 16 formed has the $R$ and $S$ absolute configurations at the diol carbon atoms as determined by X-ray analysis.

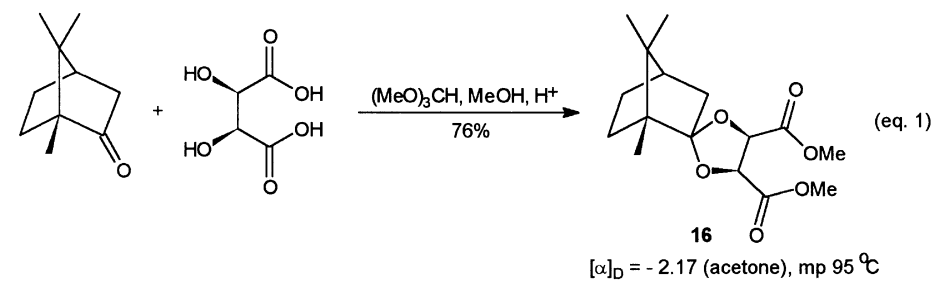

\section{Scheme 10}

Starting from 16 as a key chiral intermediate, both enantiomers of isoterrein 4 were obtained as shown in Scheme 11. Thus, treatment of $\mathbf{1 6}$ with dimethyl lithiomethylphosphonate afforded a mixture of the diastereomeric cyclopentenones $\mathbf{1 7 a}$ and $\mathbf{1 7 b}$ which were separated by fractional crystallization and column chromatography. X-ray crystal structure determination carried out on single crystals of both diastereomers established unequivocally the configuration of their diol moieties. The Horner-Wittig reaction of diastereomeric $\mathbf{1 7}$ with acetaldehyde and subsequent deprotection of the diol moiety in 18a and $\mathbf{1 8 b}$ formed gave enantiopure forms of (-)-isoterrein 4 and (+)-isoterrein $\mathbf{4}$, respectively. The enantiomeric purity of (-)-4 and (+)-4 was confirmed by ${ }^{1} \mathrm{H}-\mathrm{NMR}$ spectra recorded in the presence of $(+)-(R)$-tert-butyl(phenyl)phosphinothioic acid as a chiral solvating agent.

\section{SYNTHESIS OF RACEMIC AND OPTICALLY ACTIVE METHYL ESTER OF PROSTAGLANDIN $B_{1 \alpha}$}

To further demonstrate utility of the cycloalkenones $\mathbf{9}$ in the synthesis of natural products we selected prostaglandin $B_{1 \alpha} 6$ as a second synthetic target. The structure of $\mathbf{6}$ represents a disubstituted cyclopentenone having alkyl and alkenyl substituents at $\mathrm{C}(2)$ and $\mathrm{C}(3)$, respectively. Therefore, it was expected that 3-phosphorylmethyl-cyclopentenone $9(n=1)$ may be elaborated into 6 via regioselective 


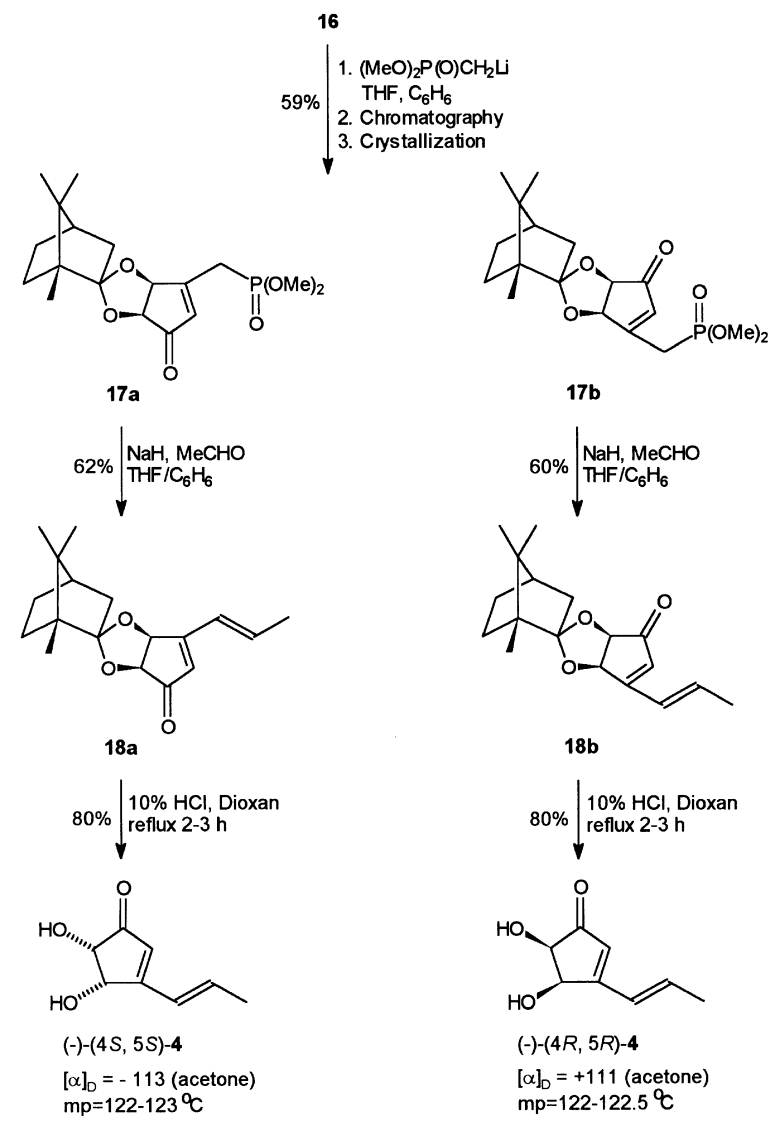

\section{Scheme 11}

alkylation and Horner-Wittig reaction. This was found to be the case [14]. Scheme 12 shows the two step synthesis of the methyl ester of prostaglandin $B_{1 \alpha} 6$ from the cyclopentenone 9 . Although the alkylation reaction of the anion derived from $\mathbf{9}(n=1)$ was not very efficient due to competitive O-alkylation, the Horner-Wittig reaction of the mono-alkylated product 19 with a dimer of $\alpha$-hydroxyheptanal occured in excellent yield affording the desired product $\mathbf{6}$ in a straightforward way.

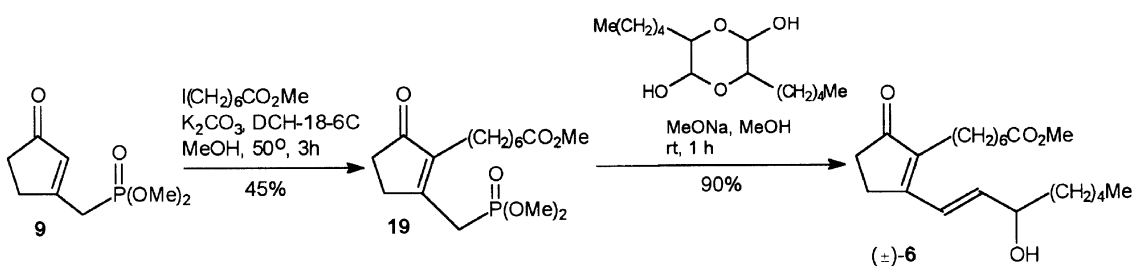

\section{Scheme 12}

In order to obtain enantiomeric forms of $\mathbf{6}$, the Horner-Wittig reaction of 19 with $(+)-(R)$-and $(-)-(S)$ $\alpha$-tert-butyldimethylsilyloxy-heptanal 20 was carried out. Desilylation of the olefination products with fluoride anion afforded enantiomeric (-)- and (+)-prostaglandins 6 (Scheme 13). However, this chiral synthesis of $\mathbf{6}$ suffers from a low yield of the olefination step and partial racemization. Its optimization is under current study.

\section{SYNTHESIS OF RACEMIC AND OPTICALLY ACTIVE SARKOMYCIN}

Sarkomycin 5 was first isolated by Umezawa et al. [15] in 1953 and its structure established in 1955 [16]. Like other cyclopentanoids, it shows both antibacterial and antitumor activity. Sarkomycin 5 possesses one stereogenic carbon atom and micro-organisms produce the levorotatory $(R)$-enantiomer. 
<smiles>CC[C@H](O)/C=C/C1=C(C)C(=O)CC1</smiles>

$(+)-6,(65 \%$ ee $)$

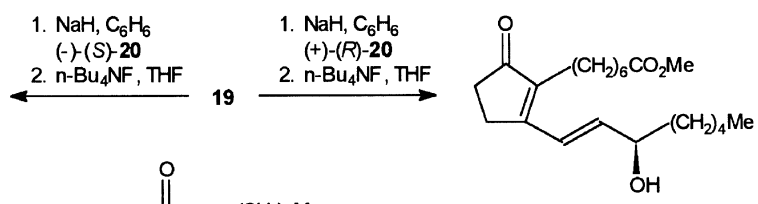

$(-)-6,(64 \%$ ee)

20

\section{Scheme 13}

In contrast to the synthesis of $\mathbf{4}$ and $\mathbf{6}$ discussed above, the synthesis of racemic sarkomycin $\mathbf{5}$ is based on a conceptually different approach. Since $\mathbf{5}$ contains the reactive $\alpha$-exocyclic methylene moiety, our strategy was to synthesize 2-diethoxyphosphoryl-3-carboxy-cyclopentanone $\mathbf{2 1}$ which should be converted into 5 via the Horner-Wittig reaction. Moreover, we decided to utilize the intramolecular carbenoid cyclization for the construction of the cyclopentanone ring. Our total synthesis of $( \pm)-\mathbf{5}$ is shown in Scheme 14 [17].

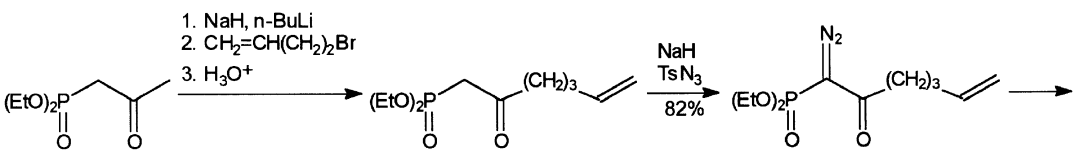<smiles>C=C[C@H]1CCC(=O)C1[R](=O)OCC</smiles>

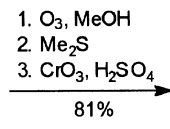<smiles>CCOC(=O)C1C(=O)CC[C@@H]1C(=O)O</smiles>
$( \pm)-21$

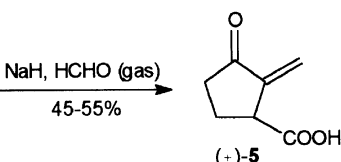

$( \pm)-5$

\section{Scheme 14}

We found that the sarkomycin precursor 21, in contrast to sarkomycin itself, is fairly chemically stable and could be resolved into enantiomers via diastereoisomeric enamine-type derivatives formed with (-)-(S)-1-(1-naphthyl)ethylamine. The Horner-Wittig reaction of enantiomeric 21 with gaseous formaldehyde afforded enantiomeric sarkomycins 5 (Scheme 15).

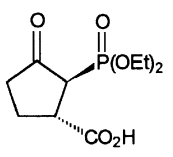

(+)-(2S, 3S)-21

$[\alpha]_{D}=+48.8$

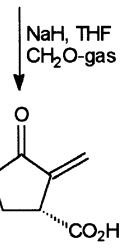

$(-)-(R)-5$

$[\alpha]_{D}=-34.7$

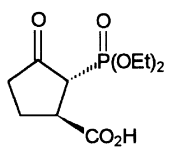

(-)-(2R, 3R)-21

$[\alpha]_{\mathrm{D}}=-48.7$

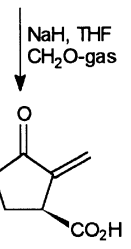

$(+)-(S)$

$[\alpha]_{D}=+33.9$

\section{Scheme 15}

It should be pointed out that this is the first synthesis of enantiopure forms of sarkomycin.

\section{SYNTHESIS OF RACEMIC ROSAPROSTOL}

The intramolecular carbenoid cyclization for the construction of cyclopentanone skeleton in combination with the Horner-Wittig reaction turned out to be also successful in the synthesis of rosaprostol 7 [18]. Rosaprostol is a trade name of 7-(2-hexyl-5-hydroxycyclopentane)-heptanoic acid which is 
a member of 19,20-bisnorprostanoic acid derivatives. The sodium salt of $\mathbf{7}$ has been launched in Italy under the name Rosal for the treatment of gastric and duodenal ulcers [19].

A total synthesis of racemic 7 is shown in Scheme 16.
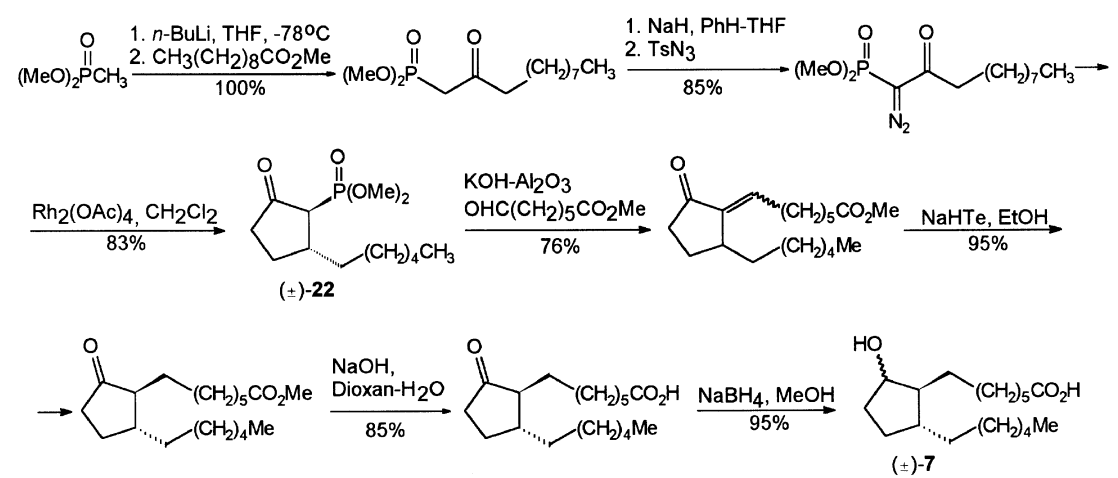

\section{Scheme 16}

It is noticeable to notice that the Horner-Wittig reaction of the intermediate 2-dimethoxyphosphorylcyclopentanone 22 was occurring efficiently when a mixture of $\mathrm{Al}_{2} \mathrm{O}_{3}$ and $\mathrm{KOH}$ was used as a base. Rosaprostol 7 obtained as above was a 1:1 mixture of trans-trans and trans-cis stereoisomers. The overall yield of our synthesis was $42 \%$ and was much higher than those reported in the literature $(<20 \%)[20]$.

\section{CONCLUSIONS}

The aim of this short review was to demonstrate that simple phosphonate reagents are useful for effecting a variety of synthetic transformations. Two general approaches to functionalized cyclopentanones and cyclopentenones have been devised. The first of them is based on cyclization of bis- $\beta$-ketophosphonates, the second involves intramolecular carbenoid cyclization. As a result of our work several naturally occurring and biologically active products have been synthesized. The typical examples are: isoterrein, sarkomycin, prostaglandin $\mathrm{B}_{1 \alpha}$ and rosaprostol.

\section{REFERENCES}

1 M. Mikolajczyk. In Reviews in Heteroatom Chemistry (S. Oae, ed.), Vol. 2, pp. 19-39. MYU, Tokyo (1993).

2 M. Mikolajczyk. S. Afr. J. Chem. 47, 103 (1994).

3 M. Mikolajczyk, S. Grzejszczak, P. Lyzwa. Tetrahedron Lett. 23, 2237 (1982).

4 M. Mikolajczyk, W. H. Midura. Zeit. Naturforsch. 416, 263 (1986).

5 M. Mikolajczyk. In Antibiotics and Antiviral Compounds (K. Krohn, H. A. Kirst, H. Maag, eds), pp. $205-213$. $\mathrm{VCH}$ (1993), and references therein.

6 P. Balczewski. Heteroatom Chem. 8, 67 (1997).

7 M. Mikolajczyk, M. Mikina. J. Org. Chem. 59, 6760 (1994).

8 H. Raistrick, G. Smith. Biochem. J. 29, 606 (1935).

9 H. C. Kolb, M. R. Hoffmann. Tetrahedron: Asymmetry 1, 237 (1990).

10 H.-J. Altenbach, W. Holzapfel. Angew. Chem. 102, 64 (1990); Angew. Chem. Int. Ed. Engl. 29, 67 (1990).

11 D. H. R. Barton, L. A. Hulshof. J. Chem. Soc., Perkin Trans. 1, 1103 (1977).

12 M. Mikina, M. Mikolajczyk. Phosphorus, Sulfur, Silicon 75, 39 (1993).

13 M. Mikolajczyk, M. Mikina, M. W. Wieczorek, J. Blaszczyk. Angew. Chem. 108, 1645 (1996); Angew. Chem. Int. Ed. Engl. 35, 1560 (1996).

14 M. Mikina. Doctoral dissertation. Centre of Molecular and Macromolecular Studies, Lódz (1997).

15 H. Umezawa, T. Takeuchi, K. Nitta, T. Yamamoto, S. Yamaoka. J. Antibiotics, Ser. A. 6, 101 (1953). 
16 I. R. Hooper, L. C. Cheney, M. J. Cron, O. B. Fardig, D. A. Johnson, D. L. Johnson, F. M. Pelermiti, H. Schmitz, W. B. Wheatley. Antibiot. Chemotherapy 5, 585 (1955).

17 M. Mikolajczyk, R. Zurawinski, P. Kielbasinski, M. W. Wieczorek, J. Blaszczyk. Synthesis, 356 (1997).

18 M. Mikolajczyk, R. Zurawinski. J. Org. Chem. 63, 8894 (1998).

19 Drugs of the Future 11, 686 (1986).

20 T. Shono, N. Kise, T. Fujimoto, N. Tominaga, H. Morita. J. Org. Chem. 57, 7125 (1992). 